\title{
Cytokine Targets in the Brain: Impact on Neurotransmitters and Neurocircuits
}

\author{
Andrew H. Miller, M.D. ${ }^{1}$, Ebrahim Haroon, M.D. ${ }^{1}$, Charles L. Raison, M.D. ${ }^{2}$, and Jennifer C. \\ Felger, Ph.D. ${ }^{1}$ \\ ${ }^{1}$ Department of Psychiatry and Behavioral Sciences, Emory University School of Medicine, \\ Atlanta, GA \\ ${ }^{2}$ Department of Psychiatry and Behavioral Sciences, University of Arizona School of Medicine, \\ Tuscon, AZ
}

\section{Abstract}

\begin{abstract}
Increasing attention has been paid to the role of inflammation in a host of illnesses including neuropsychiatric disorders such as depression and anxiety. Activation of the inflammatory response leads to release of inflammatory cytokines and mobilization of immune cells both of which have been shown to access the brain and alter behavior. The mechanisms of the effects of inflammation on the brain have become an area of intensive study. Data indicate that cytokines and their signaling pathways including p38 mitogen activated protein kinase have significant effects on the metabolism of multiple neurotransmitters such as serotonin, dopamine and glutamate through impact on their synthesis, release and reuptake. Cytokines also activate the kynurenine pathway which not only depletes tryptophan, the primary amino acid precursor of serotonin, but also generates neuroactive metabolites that can significantly influence the regulation of dopamine and glutamate. Through their effects on neurotransmitter systems, cytokines impact neurocircuits in the brain including the basal ganglia and anterior cingulate cortex, leading to significant changes in motor activity and motivation as well as anxiety, arousal and alarm. In the context of environmental challenge from the microbial world, these effects of inflammatory cytokines on the brain represent an orchestrated suite of behavioral and immune responses that subserve evolutionary priorities to shunt metabolic resources away from environmental exploration to fighting infection and wound healing, while also maintaining vigilance against attack, injury and further pathogen exposure. Chronic activation of this innate behavioral and immune response may lead to depression and anxiety disorders in vulnerable individuals.
\end{abstract}

\footnotetext{
Corresponding Author: Andrew H. Miller, M.D., Department of Psychiatry and Behavioral Sciences, Winship Cancer Institute, Emory University School of Medicine, 1365-B Clifton Rd., NE, $5^{\text {th }}$ Floor, Room B5101, Atlanta, GA, 30322 Office) 404-727-8260; FAX) 404-778-3965 amill02@emory.edu.

Financial Disclosure: All authors declare that there are no conflicts of interest, and all financial disclosures are listed for each author: Charles L. Raison has served as a consultant for Bristol Myers Squibb, Johnson and Johnson, Pamlab LLC. and Lilly and is a speaker for Pamlab LLC. and Pfizer. Dr. Raison has also developed educational presentations for Pamlab LLC., NACCME and CME Incite. Andrew H. Miller has served as a consultant for Abbott Laboratories, AstraZeneca, GlaxoSmithKline, Lundbeck Research USA, F. Hoffmann-La Roche Ltd., Johnson and Johnson, Schering-Plough Research Institute, and Wyeth/Pfizer Inc. and has received research support from Centocor Orthotec Services LLC., GlaxoSmithKline, and Schering-Plough Research Institute. Ebrahim Haroon and Jennifer C. Felger have nothing to disclose.
} 


\section{Keywords}

Inflammation; Depression; Anxiety; Basal Ganglia; Dopamine; Serotonin; Cingulate Cortex

\section{Introduction}

The role of inflammation as a common mechanism of disease including disorders such as cardiovascular disease, diabetes and cancer has been considered one of the major insights of the decade. ${ }^{[1-3]}$ The extension of this important revelation to neuropsychiatric disorders is now beginning to have a major impact in the disciplines of Psychiatry and Neurology, as researchers and clinicians alike are recognizing the importance of immune and inflammatory processes in neurodegenerative disorders, mood and anxiety disorders as well as schizophrenia. ${ }^{[1,4-6]}$ Probably, the greatest area of focus to date in Psychiatry has been on the potential role of the activated immune system in depression. ${ }^{[7,8]}$

Certain patients with major depression have been shown to exhibit all the major features of an activated immune response including increases in inflammatory cytokines in the blood and cerebrospinal fluid, and increases in blood concentrations of acute phase proteins, chemokines and adhesion molecules. ${ }^{[7]}$ All of these molecules play critical roles in the highly orchestrated innate immune inflammatory response that begins with the recognition of a "danger" signal in the form of a pathogen or the cellular constituent of a damaged or dead cell, which triggers pattern recognition receptors on phagocytic cells like macrophages to release cytokines that mediate the local inflammatory response. ${ }^{[9,10]}$ This response in turn serves to recruit relevant cell types and the release of molecules that can contain the pathogen, limit tissue damage and destruction and initiate the wound healing process. Depending on the degree or the extent of the inflammatory stimulus (e.g. a significant local injury or widespread lesions, such as the arterial plaques in atherosclerotic heart disease), the inflammatory response can go systemic, leading to the release of clinically relevant amounts of cytokines into the peripheral circulation, which can both activate the production of acute phase proteins from the liver and ultimately access the brain.

Based on the data in depression, it is apparent that only a subgroup of depressed patients exhibit increased inflammatory markers, suggesting that inflammation is one of a number of pathways that can contribute to depression. Patients who are more likely to show increased inflammation include those with treatment resistance, a history of childhood maltreatment, and obesity. ${ }^{[11-13]}$ These associations are in part due to 1) the ability of cytokines to sabotage and circumvent mechanisms of action of conventional antidepressant agents including cytokine effects on neurotransmitter function and synaptic plasticity (e.g. neurogenesis); ${ }^{[7]} 2$ ) the capacity of psychosocial stress to activate inflammatory signaling pathways, in part through stimulation of the sympathetic nervous system, ${ }^{[14]}$ and 3) the inflammatory nature of fatty tissue which contains high levels of activated macrophages responding to expanding fat cells that have outstripped their oxygen supply and have thereby become ischemic and endangered. ${ }^{[12]}$ Regarding which inflammatory measures are the most likely to be increased, at least 4 meta-analyses and/or reviews of the hundreds of papers published in this area have concluded that interleukin (IL)-6, tumor necrosis factor (TNF) 
and c-reactive protein (CRP) are the most reliably elevated in patients with major depression. ${ }^{[15-19]}$ It should be noted however that these findings may stem from factors related to assay sensitivity and the relative abundance of these cytokines in the peripheral circulation and a prominent role of other cytokines in psychopathology cannot be excluded.

As far as anxiety disorders are concerned, less attention has been paid to these diseases, although it is clear that like depression, many patients with anxiety disorders also exhibit an inflammatory phenotype. Probably the best studied to date is Post Traumatic Stress Disorder (PTSD), where a number of studies have demonstrated increases in inflammatory cytokines and their signaling pathways, including nuclear factor kappa B (NF-kB), which is a lynchpin molecule in the initiation of the inflammatory cascade and has been shown to be exquisitely stress responsive. ${ }^{[20,21]}$ Increases in inflammatory markers have also been documented in other anxiety-related conditions including panic disorder and obsessive-compulsive disorder as well as anxiety-related personality dimensions and diagnoses such as neuroticism and borderline personality disorder. ${ }^{[22-25]}$

In addition to evidence that patients with depression and anxiety disorders have increased markers of inflammation, a second body of evidence that supports the potential role of inflammation in depression and anxiety are data that administration of inflammatory stimuli can lead to symptoms of these disorders. Probably the best studied in this regard are patients receiving chronic administration of the inflammatory cytokine, interferon (IFN) alpha. IFNalpha is used to treat cancer and infectious diseases including hepatitis $\mathrm{C}$, however between $30-50 \%$ of patients administered IFN-alpha develop significant depressive symptoms as well as anxiety depending on the dose. ${ }^{[5,26]}$ Indeed, almost $50 \%$ of patients treated with high dose IFN-alpha for malignant melanoma were found to meet symptom criteria for major depression. ${ }^{[27]}$ Of note, many of the mood and anxiety symptoms induced by IFN-alpha can be blocked by pretreatment with selective serotonin reuptake inhibitors (SSRI), indicating that these symptoms may be related to cytokine effects on serotonin metabolism. ${ }^{\text {[27] }}$ Consistent with these data, patients with the short allele of the serotonin transporter gene, which imparts increased sensitivity to effects of stress on behavioral outcomes, are at increased risk of developing depression during IFN-alpha administration. ${ }^{[28,29]}$ In contrast to mood and anxiety symptoms, IFN-alpha-induced neurovegetative symptoms including fatigue and psychomotor retardation are less responsive to SSRI treatment, suggesting that distinct neurotransmitter systems and potentially neurocircuits may be involved in the variety of IFN-alpha-induced symptoms. ${ }^{[26]}$ In addition to data from IFN-alpha-treated subjects, data using other inflammatory stimuli in humans including the administration of endotoxin or typhoid vaccination to healthy volunteers has been shown to lead to behavioral changes including symptoms of depression and anxiety. ${ }^{[30-34]}$

The third body of data that supports the association of inflammation with symptoms of depression and anxiety are studies that have used drugs that inhibit inflammatory cytokines or their signaling pathways to reduce depression and anxiety. These studies, which are far fewer in number than the correlational studies noted above, address more directly the cause and effect relationship between inflammation and behavioral disturbances. The largest study to date in this regard is a double blind placebo controlled trial of the TNF inhibitor, etanercept, in patients with psoriasis. ${ }^{[35]}$ Patients treated with etanercept $(n=311)$ showed a 
significant improvement on the Beck Depression Inventory compared to patients who received placebo $(n=309)$. Of note, the improvement in depressive symptoms was independent of improvement of other disease-related symptoms including joint pain and skin lesions. Unfortunately, the sample was not primarily depressed, and the difference in BDI scores between groups was less than 2 points. More recently, the TNF inhibitor infliximab was given to patients with treatment resistant depression in a randomized placebo controlled trial. ${ }^{[36]}$ In this study, infliximab reduced depression and anxiety symptoms, but only in patients with increased inflammation as measured by CRP. This study which included 30 subjects per group was underpowered to detect significant differences in the subsample of individuals with high inflammation $(\mathrm{CRP}>5 \mathrm{mg} / \mathrm{L})(\mathrm{n}=22)$. However, the identification of an inflamed subgroup of depressed patients that might be especially responsive to an immunetargeted therapy is promising regarding the personalization of treatment of mood and anxiety disorders. Finally, several smaller studies have indicated that administration of antiinflammatory agents including cyclooxygenase 2 inhibitors or acetylsalicylic acid may have antidepressant efficacy. ${ }^{[37-39]}$ Taken together, these preliminary findings indicate that inhibition of inflammation may have antidepressant properties but potentially only in the subgroup of patients with increased inflammatory markers.

\section{Inflammatory Access to the Brain}

Given the findings that depression and anxiety are strongly linked with increased inflammation, possibly in a cause and effect manner with translational implications, there has been great interest in how peripheral inflammatory responses access the brain. In general there have been 3 major pathways that have been described, all of which appear to be relevant both in the context of the administration of an inflammatory stimulus and the exposure to stress. These pathways include 1) "humoral" routes that involve passage of circulating cytokines through leaky regions in the blood brain barrier such as the circumventricular organs and active transport of circulating cytokines into brain parenchyma via cytokine specific saturable transporters, ${ }^{[40]} 2$ ) a neural route which involves activation of cytokine receptors on afferent nerve fibers that then transduce cytokine signals to the brain ${ }^{[41,42]}$ and 3) a cellular route whereby chemokines released by activated microglia, the primary inflammatory cell type in the brain, and adhesion molecules expressed in the CNS can attract activated peripheral cell types including monocytes and $\mathrm{T}$ cells to the meninges and brain parenchyma. ${ }^{[43,44]}$ These data, derived almost exclusively from animal models, are consistent with human studies that have indicated that administration of peripheral cytokines such as IFN-alpha to patients with hepatitis $\mathrm{C}$ is associated with activation of a central inflammatory response associated with increased cerebrospinal fluid (CSF) concentrations of IL-6 and the chemokine, monocyte chemoattractant protein-1 (MCP-1), ${ }^{[45]}$ which has been shown to attract monocytes to the brain in the context of peripheral immune activation. ${ }^{[43]}$ This activation of a central inflammatory response has also been shown to correlate with changes in neurotransmitter metabolism and stimulation of the kynurenine pathway leading to increases in CSF concentrations of the neuroactive metabolites kynurenic acid and quinolinic acid (see below). ${ }^{[45,46]}$

One major drawback in the research on the link between peripheral and central inflammation is the limited availability of neuroimaging techniques and ligands [e.g. for positron emission 
tomography (PET)] that can detect inflammation in the brain in humans with subtle neuroinflammatory responses, as might be expected in patients with depression and anxiety disorders. For example, available PET ligands including PK1195 which binds to the translocator protein (TSPO), formerly known as the peripheral benzodiazepine receptor, that is upregulated in activated microglia, can only detect marked increases in CNS inflammatory responses typically associated with end stage diseases in which significant CNS cellular damage and death has occurred such as in late stage neurodegenerative disorders including Parkinson's disease, Alzheimer's disease, and multiple sclerosis (MS) as well as infectious diseases such as the dementia secondary to infection with human immunodeficiency virus (HIV). ${ }^{[47,48]}$ Although new ligands for the TSPO are currently under development, they are not ready for more general use in research or clinical settings. ${ }^{[4]}$ Other techniques that are being developed for examining inflammation in the brain but are also not ready for general application, include magnetic resonance spectroscopy and resting state functional magnetic resonance imaging (fMRI).

\section{Cytokine Effects on Neurotransmitter Function}

Given that activation of peripheral inflammatory responses have been associated with mood and anxiety disorders and that peripheral immune activation can spread to the CNS, there has been great interest in the impact of cytokines and their signaling pathways on neurotransmitter systems known to be associated with depression and anxiety including serotonin, norepinephrine, dopamine and glutamate. There is a rich animal literature which describes the acute and sub-chronic effects of cytokines on neurotransmitter systems in the brain that has been extensively reviewed elsewhere. ${ }^{[49,50]}$ Therefore, the following discussion will focus on mechanisms by which cytokines can influence neurotransmitter metabolism with an emphasis on cytokine signaling pathways and enzyme systems involved in the synthesis, reuptake and release of relevant neurotransmitters. Of note, our attention will be focused on the potential disruptive effects of increased inflammatory cytokines on neurotransmitter function. Nevertheless, it should be appreciated that under physiologic conditions, cytokines play essential roles in neuroplasticity including neurogenesis, synaptic scaling and remodeling, long term potentiation, and learning and memory. ${ }^{[51-53]}$ In addition, recent data suggest that activation of cytokines including TNF and IFN-gamma may play an important role in the molecular and behavioral response to antidepressants. ${ }^{[54]}$ These findings underline the complexity by which inflammatory cytokines act in the brain and underscore the importance of identifying subgroups of patients with and without increased inflammation in the periphery and/or CNS for targeted treatment of the contribution of inflammation to behavioral disturbances.

\section{Synthesis}

There are at least 2 major pathways by which inflammatory cytokines can influence the synthesis of monoamine neurotransmitters. First, inflammatory cytokines and their signaling pathways can activate the enzyme, indoleamine 2,3 dioxygenase (IDO). ${ }^{[55]}$ IDO converts tryptophan, the primary amino acid of serotonin, into kynurenine, thus potentially depleting the availability of serotonin in the brain. Activation of IDO in the brain has been shown to play a critical role in the development of depressive-like behavior in rodents in the context 
of both the administration of endotoxin and infection with the mycobacterium, Bacille Calmette-Guerin (BCG). ${ }^{[56,57]}$ Indeed, inhibition of IDO using 1 methyl-tryptophan (1-MT) or the use of IDO deficient mice has been shown to reverse the depressogenic effects of endotoxin and BCG in mice. In human studies, increases in kynurenine and decreases in tryptophan have been associated with major depression and depressive symptom severity in patients administered IFN-alpha for cancer or infectious disease. ${ }^{[58,59]}$ Of note, kynurenine can be converted to kynurenic acid (KYNA) in astrocytes and quinolinic acid (QUIN) in microglia, and patients treated with IFN-alpha has been found to exhibit increased KYNA and QUIN in the CSF, indicating that kynurenine can access the brain and be converted to its neuroactive metabolites (see below). ${ }^{[46]}$

Another mechanism by which inflammatory cytokines can influence the synthesis of monoamine neurotransmitters is through the disruption of tetrahydrobiopterin (BH4). $\mathrm{BH} 4$ is an essential enzyme co-factor for tryptophan hydroxylase and tyrosine hydroxylase, which are the rate limiting enzymes for the synthesis of serotonin and dopamine (as well as norepinephrine), respectively. ${ }^{[60]} \mathrm{BH} 4$ is also required for the activity of phenylalanine hydroxylase which converts phenylalanine (Phe) to tyrosine (Tyr). The Phe/Tyr ratio has been used as an indirect measure of BH4 activity in the brain and has been correlated with increased inflammatory markers in medically ill patients and symptoms of depression in cytokine-treated patients and elderly individuals. ${ }^{[61-63]}$ Recent data in IFN-alpha-treated patients have more directly linked the Phe/Tyr ratio with dopamine metabolism in the brain. ${ }^{[64]}$ Indeed, significant correlations were found between this ratio and CSF concentrations of both dopamine and its metabolite, homovanillic acid. ${ }^{[64]}$ Moreover, in this study, increased IL-6 in the CSF was associated with decreased CSF BH4.

Although inflammation and cytokines have been shown to induce GTP-cyclohydrolase I, an enzyme responsible for BH4 synthesis, ${ }^{[65]}$ inflammatory cytokines can disrupt BH4 through two potential mechanisms. First, BH4 is an enzyme co-factor for the conversion of arginine to nitric oxide (NO) by nitric oxide synthase (NOS). ${ }^{[60]}$ Inflammatory cytokines can stimulate NOS to produce NO. The increased activity of NOS can thereby increase the utilization of $\mathrm{BH} 4$ which is converted to $\mathrm{BH} 2$ during the reaction. Inhibition of NOS has been shown to both increase $\mathrm{BH} 4$ and dopamine concentrations in the brain of rats treated with IFN-alpha. ${ }^{[66]}$ In addition to increased BH4 utilization, inflammatory cytokines also can contribute to an oxidative state through generation of both nitrogen and oxygen radicals. BH4 is very sensitive to oxidative stress which can lead to irreversible degradation of BH4 to dihydroxyanthopterin. ${ }^{[62]}$

\section{Reuptake}

Through activation of signaling pathways including mitogen activated protein kinase (MAPK) such as p38 MAPK, inflammatory cytokines have been shown to increase the expression and function of the reuptake pumps (transporters) for serotonin, norepinephrine and dopamine. Most of the work in this area has focused on serotonin where in both rat cell lines and rat midbrain and striatal synaptosomes, TNF and IL-1 have been shown to increase expression and activity of the serotonin transporter (SERT) in a time and dose dependent fashion in vitro. ${ }^{[67,68]}$ These effects were reversed by pharmacologic inhibition of $\mathrm{p} 38$ 
MAPK. Mice treated with endotoxin also exhibit increases in SERT activity which were paralleled by depressive-like behavior as reflected by increased immobility in the forced swim test and tail suspension test. ${ }^{[69]}$ Both of these endotoxin-induced changes were reversible by administration of a pharmacologic p38 inhibitor. Consistent with these findings, in vivo data in maltreated rhesus monkeys has demonstrated a relationship between activation of p38 MAPK as measured in peripheral blood mononuclear cells and reduced concentrations of CSF 5-hydroxyindoleacetic acid, a primary serotonin metabolite. ${ }^{[70]}$ MAPK pathways have also been associated with functioning of the dopamine transporter, where activation of MAPK kinase (MEK) has been shown to increase dopamine reuptake in cell lines, and treatment of rat striatal synaptosomes with MEK inhibitors was associated with a decrease in dopamine reuptake. ${ }^{[71]}$

\section{Release}

A third mechanism by which inflammatory cytokines can influence neurotransmitter function is through effects on release. For example, administration of IFN-alpha to patients with hepatitis $\mathrm{C}$ has been shown to increase the reuptake and decrease the release of radiolabeled dopa, the primary precursor of dopamine. ${ }^{[72]}$ These findings may be related to the production of KYNA in the brain as a consequence of IDO activation as previously described. Indeed, intrastriatal administration of KYNA has been shown to decrease extracellular dopamine using in vivo microdialysis in rats, ${ }^{[73]}$ an effect that appears to be mediated by the $a 7$ subunit of the nicotinic acetylcholine receptor. ${ }^{[74]}$ Inflammatory cytokines have also been shown to stimulate the release of glutamate from astrocytes and reduce astrocytic expression of glutamate transporters, potentially leading to increased glutamate excitotoxicity. ${ }^{[7,75,76]}$ Of note, release of glutamate by astrocytes is more likely to access extrasynaptic NMDA receptors which have been shown to lead to decreased brain derived neurotrophic factor, which is important in neurogenesis. ${ }^{[77]}$ Activation of IDO also leads to the production of QUIN which can directly stimulate the n-methyl-d-aspartate (NMDA) receptor, thereby further contributing to excessive glutamatergic signaling. ${ }^{[7]}$ Increased CSF concentrations of QUIN have been associated with increased depressive symptoms in patients treated with IFN-alpha. ${ }^{[46]}$

Finally, there is less known about the effects of inflammatory cytokines on other neurotransmitter systems in the brain that play a role in depression and anxiety including gamma-aminobutyric acid (GABA) and acetylcholine. Nevertheless, there is emerging data regarding interactions between inflammatory cytokines and these neurotransmitter systems that may have profound consequences for immune regulation. For example, studies in rodents have indicated that GABA can reduce the release of inflammatory cytokines through inhibition of NF-kB and p38 MAPK signaling pathways, ${ }^{[78]}$ and decrease the progression of experimental autoimmune encephalomyelitis, an animal model of MS. ${ }^{[79]}$ Interestingly, CSF from MS patients with enhanced brain lesions inhibited GABA transmission in mouse brain slices, an effect that could be blocked with an IL-1-beta, anatgonist. ${ }^{\left[{ }^{[0]}\right.}$ These findings indicate that inflammation in the CNS may decrease GABAergic tone, which could further fuel inflammatory cytokine production. Additionally, inflammatory cytokines, such as IL-1, can increase neuronal acetylcholinesterase expression and activity, and has been shown to directly inhibit acetylcholine release from hippocampal neurons. ${ }^{\left[{ }^{[1,82]}\right.}$ Of relevance to 
inflammation, through binding to muscarinic receptors in the brain, acetylcholine has been shown to reduce cytokine production in the periphery through the "cholinergic antiinflammatory reflex" ${ }^{[83]}$ Taken together, these findings indicate that a potential decrease in release of GABA and acetylcholine in the brain in response to inflammatory cytokines may promote inflammatory responses.

\section{Cytokines and Neurocircuits}

The panoply of mechanisms and pathways by which cytokines can influence neurotransmitter metabolism in the brain have led investigators to investigate which brain regions are most affected by the activation of the inflammatory response. Although some clues have been revealed by investigation of the neuropsychological changes induced by the administration of cytokines or cytokine inducers, the majority of studies to date have utilized neuroimaging strategies such as PET and fMRI to investigate the impact of cytokines on specific brain circuits. Taken together, the literature indicates that primary CNS targets include the basal ganglia (ventral striatum in particular) and the dorsal anterior cingulate cortex (ACC)(Figure 1). Other brain regions are also engaged including the amygdala, hippocampus, insula, dorsolateral prefrontal cortex and subgenual ACC. ${ }^{[33,34,84-86]}$ The focus of this review will be on the basal ganglia and dorsal ACC.

\section{The Basal Ganglia: Motor Activity and Motivation}

Some of the first data on the involvement of specific brain regions in the effects of cytokines on the CNS were from patients receiving IFN-alpha for either cancer or infectious disease. Early findings were from PET studies examining glucose metabolism using 18Ffluorodeoxyglucose in these IFN-alpha-treated patient populations. ${ }^{\left[{ }^{[5,87]}\right.}$ Regardless of whether IFN-alpha was being administered for malignant melanoma or hepatitis $\mathrm{C}$, independent studies revealed increased basal ganglia glucose metabolism that was most prominent in the caudate, putamen and globus pallidus. ${ }^{[85,87]}$ Interestingly, increased glucose metabolism in basal ganglia nuclei have been previously observed in Parkinson's disease, where it is believed to reflect increased oscillatory burst activity in basal ganglia neurons normally under inhibitory control of dopamine. ${ }^{[88-90]}$ Consistent with this potential overlap of cytokine effects on the basal ganglia and Parkinson's disease are case reports of patients developing Parkinson's-like symptoms during IFN-alpha treatment that were relieved by levodopa. ${ }^{[91]}$ In addition to these early neuroimaging studies, computerized neuropsychological testing of IFN-alpha-treated patients revealed motor slowing that correlated with symptoms of both depression and fatigue. ${ }^{[92]}$

More recent studies have examined basal ganglia function in IFN-alpha-treated patients with hepatitis $\mathrm{C}$ using fMRI. These studies have revealed significant decreased activation of ventral striatal regions during a hedonic reward task, which in turn was highly correlated with decreased motivation and increased fatigue. ${ }^{[72]}$ To further explore the potential neurotransmitter changes that might be associated with these alterations in basal ganglia function, PET imaging studies using 18-F fluorodopa (Fdopa) have been conducted. ${ }^{\text {[72] }}$ Fdopa is taken up by dopaminergic neurons and converted by aromatic amino acid decarboxylase (AADC) into dopamine, which is then stored and ultimately released. PET imaging using Fdopa can measure both the uptake and turnover (release) of Fdopa, 
providing some insight into presynaptic dopamine function. Data from patients administered IFN-alpha have indicated that in regions that overlap with those identified in the fMRI study described above (e.g. ventral striatum) there was increased Fdopa uptake and decreased Fdopa turnover. ${ }^{[72]}$ These changes in presynaptic dopamine function were also correlated with changes in behavior including depression, fatigue and other sickness symptoms including cognitive dysfunction. Increased Fdopa uptake may represent increased activity of AADC, which could be secondary to dopamine depletion (decreased synthesis) as described above. Indeed, increased AADC activity has been observed in the context of decreased dopamine availability or dopamine signaling for example after administration of the monoamine depleting drug reserpine or dopamine receptor antagonists (e.g. haloperidol), respectively. ${ }^{[93]}$ The decreased dopamine turnover/release is also of interest and may reflect changes in CSF kynurenine metabolites such as KYNA which as discussed above have been observed in IFN-alpha-treated patients and have been shown to reduce dopamine release. ${ }^{[73]}$

Consistent with observations in IFN-alpha-treated patients, investigators have also observed basal ganglia changes following the administration of other inflammatory stimuli including endotoxin and typhoid vaccination. For example, administration of endotoxin to healthy volunteers was found to lead to significant decreases in the activation of the ventral striatum to a monetary reward cue during fMRI scanning. ${ }^{[30]}$ Decreased striatal activation was in turn associated with endotoxin-induced symptoms of depression. Vaccination of healthy volunteers with Salmonella typhi has also been associated with changes in neural activity in the basal ganglia. ${ }^{[32]}$ Indeed, administration of typhoid vaccination was associated with increased activation in substantia nigra during a task of low-level visual stimulation. ${ }^{[32]}$ Increased neural activity in the substantia nigra was in turn correlated with increases in IL-6 as well as psychomotor slowing. ${ }^{[32]}$ Taken together, the consistency of neuroimaging data across immune stimuli suggest that basal ganglia nuclei are a primary target of cytokine effects on the brain, leading to changes in motivation and motor activity and likely being secondary to cytokine effects on dopamine function.

\section{Anterior Cingulate Cortex: Anxiety, Arousal and Alarm}

A second major CNS target of cytokines that has received considerable attention is the dorsal ACC. The dorsal ACC [Broadman's Area (BA) 24] has been shown to play an important role in error detection and conflict monitoring. ${ }^{[94]}$ In addition, the dACC has been found to process social pain and therefore has been suggested to comprise a neural "alarm system", which can both detect and respond to threatening environmental stimuli in the social domain. ${ }^{[95]}$ For example, activation of the dACC was found during a fMRI task of

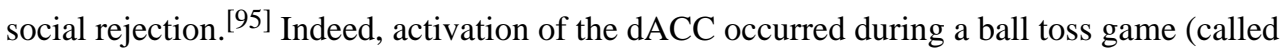
the "Cyberball" task) at a time corresponding to a point in the game when the subject was excluded (social rejection). dACC activation during social rejection was associated with emotional distress, and is consistent with the role of this brain region in processing social pain. ${ }^{[95]}$ The dACC's downstream activation of the autonomic arousal system provides a further component of this alarm system which can thus both identify and respond to social threat cognitively, emotionally and physically. ${ }^{[96]}$ 
Early work in patients treated with IFN-alpha using fMRI and a task of visuo-spatial attention demonstrated that chronic IFN-alpha administration was associated with increased dACC activation. ${ }^{[97]}$ Activation of the dACC was highly correlated with the number of taskrelated errors made by IFN-alpha-treated patients, whereas no correlation was found between dACC activation and task-related errors in controls. ${ }^{[97]}$ Of note, the error rate for the task was low in both groups and did not differ between groups. Increased activation of the dACC in the context of low error rates has also been observed in individuals with hightrait anxiety. ${ }^{[98]}$ In addition, increased dACC activation has been found in subjects with increased neuroticism and obsessive compulsive disorder, both of which are associated with increased anxiety and arousal as well as increased inflammatory markers. ${ }^{[99,100]}$ Administration of typhoid vaccination has also been shown to lead to increased dACC activation using fMRI and the Stroop task, which through its presentation of congruent and non-congruent stimuli has been shown in multiple studies to increase blood flow to the dACC. ${ }^{[33,95]}$ Interestingly, recent data suggest that the inflammatory response to a laboratory speech stressor as measured by the soluble TNF receptor II predicts the subsequent intensity with which subjects experience social rejection during the Cyberball task, indicating a link between the inflammatory and cognitive response to stress. ${ }^{[101]}$ Taken together, these data indicate that cytokines can increase the reactivity of the AACC and thereby may increase sensitivity of the organism to the external environment especially as it relates to the potential threatening nature of social conspecifics.

\section{The Evolutionary Context}

When considering the possible adaptive nature of cytokine effects on the brain, it is readily apparent that the impact of cytokines on the basal ganglia leads to decreased motivation and motor activity, which in turn serve to reduce the metabolic costs of environment exploration, thereby conserving energy resources for mounting a fever, fighting infection and wound healing. ${ }^{[102]}$ In contrast, activation of dACC pathways sounds the alarm and puts a wounded or sick animal that is vulnerable to attack on hyper-alert status (Figure 1). Thus, in combination, the effects of cytokines on these neurocircuits subserve competing evolutionary survival priorities to lay low and conserve energy (the conservation/withdrawal response) while remaining on guard against future attack (the hypervigilance response). ${ }^{[102]}$ While these behavioral priorities are an essential component of the successful immunologic response to trauma or infection, in the context of chronic inflammation, this response can quickly become maladaptive, leading to chronic withdrawal (depression) and hypervigilance (anxiety). ${ }^{[103]}$

Interestingly, the survival and thus evolutionary value of an aggressive immune and behavioral response to infectious challenge cannot be overestimated, given the intensive selection pressure applied by childhood death secondary to infectious agents in ancestral (and even modern) environments. In an analysis of candidate genes that have been associated with depression and confirmed in meta-analyses of genome-wide association studies, many of these genes have direct roles in protection against pathogens, suggesting that the reason that depression-related genes have remained in the gene pool is related to their adaptive value in the microbial world, not the social world. ${ }^{[102]}$ Indeed, increasing recognition is given to modern man's legacy of increased inflammation which not only 
includes a variety of medical disorders but also a host of neuropsychiatric diseases including both depression and anxiety. Thus managing inflammatory responses becomes a therapeutic challenge for many medical specialties including Psychiatry.

\section{Summary and Conclusions}

Based on the data gathered to date, there is strong evidence that there is a link between depression and anxiety disorders and inflammation. This link is most apparent in certain patients including those who are treatment resistant, victims of childhood maltreatment, and those who are obese. Although the behavioral responses that are associated with inflammation are an important part of the response to resolving an immune challenge, chronic activation of the inflammatory response (i.e. non-resolving inflammation) can contribute to states of depression and anxiety through a multiplicity effects on neurotransmitter metabolism and neurocircuitry relevant to these diseases. Translational implications include the identification of anxious and depressed patients with increased inflammation using relevant biomarkers including CRP, whose recommended classification into low $(<1 \mathrm{mg} / \mathrm{L})$, medium $(1-3 \mathrm{mg} / \mathrm{L})$ and high $(>3 \mathrm{mg} / \mathrm{L})$, provides an excellent starting point for researchers and clinicians. Indeed, as described above, only depressed patients with a CRP $>5 \mathrm{mg} / \mathrm{L}$ showed meaningful separation from placebo in the context of treatment with a cytokine antagonist. While immune-targeted therapies may represent a viable option for many patients with increased inflammation and depression or anxiety, for some patients, especially those with chronic medical conditions (who may not tolerate aggressive antiinflammatory strategies), treatment may have to be targeted to the more downstream consequences of immune activation. Such targets may include the kynurenine pathway, the availability of $\mathrm{BH} 4$ and the impact of cytokines on dopamine and glutamate metabolism, which are not readily addressed by conventional antidepressant treatments. Nevertheless, the opportunity to personalize therapies for anxiety and depression through the identification of biomarkers which reflect activation of relatively specific and unique pathophysiologic pathways related to inflammation holds great promise for our field, and represents an important step in tailoring our treatments to optimize therapeutic success.

\section{Acknowledgments}

This work was supported in part by PHS grants from the National Institute of Mental Health (R01MH087604, R01MH083746, R01MH075102, R21 MH0771172 to AHM and PHS grants K23 MH091254 to EH and F32 MH093054 to JCF) as well as PHS Grant UL1 RR025008 from the Clinical and Translational Science Award program, National Institutes of Health, National Center for Research Resources.

\section{References}

1. Couzin-Frankel J. Inflammation bares a dark side. Science. 2010; 330(6011):1621. [PubMed: 21163993]

2. Aggarwal BB, Shishodia S, Sandur SK, et al. Inflammation and cancer: how hot is the link? Biochem Pharmacol. 2006; 72(11):1605-21. [PubMed: 16889756]

3. Ridker PM. Inflammatory biomarkers and risks of myocardial infarction, stroke, diabetes, and total mortality: implications for longevity. Nutr Rev. 2007; 65(12 Pt 2):S253-9. [PubMed: 18240558]

4. Czirr E, Wyss-Coray T. The immunology of neurodegeneration. J Clin Invest. 2012; 122(4):115663. [PubMed: 22466657] 
5. Raison CL, Capuron L, Miller AH. Cytokines sing the blues: inflammation and the pathogenesis of depression. Trends Immunol. 2006; 27(1):24-31. [PubMed: 16316783]

6. Muller N. Inflammation and the glutamate system in schizophrenia: implications for therapeutic targets and drug development. Expert Opin Ther Targets. 2008; 12(12):1497-507. [PubMed: 19007319]

7. Miller AH, Maletic V, Raison CL. Inflammation and its discontents: the role of cytokines in the pathophysiology of major depression. Biol Psychiatry. 2009; 65(9):732-41. [PubMed: 19150053]

8. Maes M. Evidence for an immune response in major depression: a review and hypothesis. Prog Neuropsychopharmacol Biol Psychiatry. 1995; 19(1):11-38. [PubMed: 7708925]

9. Hirsiger S, Simmen HP, Werner CM, et al. Danger signals activating the immune response after trauma. Mediators Inflamm. 2012; 315941:19.

10. Abbas, AKL.; AH. Cellular and Molecular Immunology. Philadelphia, PA: Saunders; 2003.

11. Danese A, Moffitt TE, Pariante CM, et al. Elevated inflammation levels in depressed adults with a history of childhood maltreatment. Arch Gen Psychiatry. 2008; 65(4):409-15. [PubMed: 18391129]

12. Shelton RC, Miller AH. Eating ourselves to death (and despair): the contribution of adiposity and inflammation to depression. Prog Neurobiol. 2010; 91(4):275-99. [PubMed: 20417247]

13. Lanquillon S, Krieg JC, Bening-Abu-Shach U, Vedder H. Cytokine production and treatment response in major depressive disorder. Neuropsychopharmacology. 2000; 22(4):370-9. [PubMed: 10700656]

14. Bierhaus A, Wolf J, Andrassy M, et al. A mechanism converting psychosocial stress into mononuclear cell activation. Proc Natl Acad Sci U S A. 2003; 100(4):1920-5. [PubMed: 12578963]

15. Dowlati Y, Herrmann N, Swardfager W, et al. A meta-analysis of cytokines in major depression. Biol Psychiatry. 2010; 67(5):446-57. [PubMed: 20015486]

16. Howren MB, Lamkin DM, Suls J. Associations of depression with C-reactive protein, IL-1, and IL-6: a meta-analysis. Psychosom Med. 2009; 71(2):171-86. [PubMed: 19188531]

17. Zorrilla EP, Luborsky L, McKay JR, et al. The relationship of depression and stressors to immunological assays: a meta-analytic review. Brain Behav Immun. 2001; 15(3):199-226. [PubMed: 11566046]

18. Hiles SA, Baker AL, de Malmanche T, Attia J. A meta-analysis of differences in IL-6 and IL-10 between people with and without depression: exploring the causes of heterogeneity. Brain Behav Immun. 2012; 26(7):1180-8. [PubMed: 22687336]

19. Mossner R, Mikova O, Koutsilieri E, et al. Consensus paper of the WFSBP Task Force on Biological Markers: biological markers in depression. World J Biol Psychiatry. 2007; 8(3):141-74. [PubMed: 17654407]

20. Pace TW, Heim CM. A short review on the psychoneuroimmunology of posttraumatic stress disorder: from risk factors to medical comorbidities. Brain Behav Immun. 2011; 25(1):6-13. [PubMed: 20934505]

21. Pace TW, Wingenfeld K, Schmidt I, et al. Increased peripheral NF-kappaB pathway activity in women with childhood abuse-related posttraumatic stress disorder. Brain Behav Immun. 2012; 26(1):13-7. [PubMed: 21801830]

22. Hoge EA, Brandstetter K, Moshier S, et al. Broad spectrum of cytokine abnormalities in panic disorder and posttraumatic stress disorder. Depress Anxiety. 2009; 26(5):447-55. [PubMed: 19319993]

23. Kahl KG, Bens S, Ziegler K, et al. Cortisol, the cortisol-dehydroepiandrosterone ratio, and proinflammatory cytokines in patients with current major depressive disorder comorbid with borderline personality disorder. Biol Psychiatry. 2006; 59(7):667-71. [PubMed: 16199015]

24. Konuk N, Tekin IO, Ozturk U, et al. Plasma levels of tumor necrosis factor-alpha and interleukin-6 in obsessive compulsive disorder. Mediators Inflamm. 2007; 2007:65704. [PubMed: 17497035]

25. Sutin AR, Terracciano A, Deiana B, et al. High neuroticism and low conscientiousness are associated with interleukin-6. Psychol Med. 2010; 40(9):1485-93. [PubMed: 19995479] 
26. Capuron L, Gumnick JF, Musselman DL, et al. Neurobehavioral effects of interferon-alpha in cancer patients: phenomenology and paroxetine responsiveness of symptom dimensions. Neuropsychopharmacology. 2002; 26(5):643-52. [PubMed: 11927189]

27. Musselman DL, Lawson DH, Gumnick JF, et al. Paroxetine for the prevention of depression induced by high-dose interferon alfa. N Engl J Med. 2001; 344(13):961-6. [PubMed: 11274622]

28. Lotrich FE, Ferrell RE, Rabinovitz M, Pollock BG. Risk for depression during interferon-alpha treatment is affected by the serotonin transporter polymorphism. Biol Psychiatry. 2009; 65(4): 344-8. [PubMed: 18801474]

29. Bull SJ, Huezo-Diaz P, Binder EB, et al. Functional polymorphisms in the interleukin-6 and serotonin transporter genes, and depression and fatigue induced by interferon-alpha and ribavirin treatment. Mol Psychiatry. 2008

30. Eisenberger NI, Berkman ET, Inagaki TK, et al. Inflammation-induced anhedonia: endotoxin reduces ventral striatum responses to reward. Biol Psychiatry. 2010; 68(8):748-54. [PubMed: 20719303]

31. Reichenberg A, Yirmiya R, Schuld A, et al. Cytokine-associated emotional and cognitive disturbances in humans. Arch Gen Psychiatry. 2001; 58(5):445-52. [PubMed: 11343523]

32. Brydon L, Harrison NA, Walker C, et al. Peripheral inflammation is associated with altered substantia nigra activity and psychomotor slowing in humans. Biol Psychiatry. 2008; 63(11): 1022-9. [PubMed: 18242584]

33. Harrison NA, Brydon L, Walker C, et al. Neural origins of human sickness in interoceptive responses to inflammation. Biol Psychiatry. 2009; 66(5):415-22. [PubMed: 19409533]

34. Harrison NA, Brydon L, Walker C, et al. Inflammation causes mood changes through alterations in subgenual cingulate activity and mesolimbic connectivity. Biol Psychiatry. 2009; 66(5):407-14. [PubMed: 19423079]

35. Tyring S, Gottlieb A, Papp K, et al. Etanercept and clinical outcomes, fatigue, and depression in psoriasis: double-blind placebo-controlled randomised phase III trial. Lancet. 2006; 367(9504):2935. [PubMed: 16399150]

36. Raison CL, Rutherford RE, Woolwine BJ, et al. A Randomized Controlled Trial of the Tumor Necrosis Factor Antagonist Infliximab for Treatment-Resistant Depression: The Role of Baseline Inflammatory Biomarkers. Arch Gen Psychiatry. 2012:1-11.

37. Muller N, Schwarz MJ, Dehning S, et al. The cyclooxygenase-2 inhibitor celecoxib has therapeutic effects in major depression: results of a double-blind, randomized, placebo controlled, add-on pilot study to reboxetine. Mol Psychiatry. 2006; 11(7):680-4. [PubMed: 16491133]

38. Brunello N, Alboni S, Capone G, et al. Acetylsalicylic acid accelerates the antidepressant effect of fluoxetine in the chronic escape deficit model of depression. Int Clin Psychopharmacol. 2006; 21(4):219-25. [PubMed: 16687993]

39. Mendlewicz J, Kriwin P, Oswald P, et al. Shortened onset of action of antidepressants in major depression using acetylsalicylic acid augmentation: a pilot open-label study. Int Clin Psychopharmacol. 2006; 21(4):227-31. [PubMed: 16687994]

40. Quan N, Banks WA. Brain-immune communication pathways. Brain Behav Immun. 2007; 21(6): 727-35. [PubMed: 17604598]

41. Luheshi GN, Bluthe RM, Rushforth D, et al. Vagotomy attenuates the behavioural but not the pyrogenic effects of interleukin-1 in rats. Auton Neurosci. 2000; 85(1-3):127-32. [PubMed: 11189019]

42. Watkins LR, Goehler LE, Relton JK, et al. Blockade of interleukin-1 induced hyperthermia by subdiaphragmatic vagotomy: evidence for vagal mediation of immune-brain communication. Neurosci Lett. 1995; 183(1-2):27-31. [PubMed: 7746479]

43. D'Mello C, Le T, Swain MG. Cerebral microglia recruit monocytes into the brain in response to tumor necrosis factoralpha signaling during peripheral organ inflammation. J Neurosci. 2009; 29(7):2089-102. [PubMed: 19228962]

44. Lewitus GM, Cohen H, Schwartz M. Reducing post-traumatic anxiety by immunization. Brain Behav Immun. 2008; 22(7):1108-14. [PubMed: 18562161] 
45. Raison CL, Borisov AS, Majer M, et al. Activation of central nervous system inflammatory pathways by interferon-alpha: relationship to monoamines and depression. Biol Psychiatry. 2009; 65(4):296-303. [PubMed: 18801471]

46. Raison CL, Dantzer R, Kelley KW, et al. CSF concentrations of brain tryptophan and kynurenines during immune stimulation with IFN-alpha: relationship to CNS immune responses and depression. Mol Psychiatry. 2010; 15(4):393-403. [PubMed: 19918244]

47. Ching AS, Kuhnast B, Damont A, et al. Current paradigm of the 18-kDa translocator protein (TSPO) as a molecular target for PET imaging in neuroinflammation and neurodegenerative diseases. Insights Imaging. 2012; 3(1):111-9. [PubMed: 22696004]

48. Schweitzer PJ, Fallon BA, Mann JJ, Kumar JS. PET tracers for the peripheral benzodiazepine receptor and uses thereof. Drug Discov Today. 2010; 15(21-22):933-42. [PubMed: 20800696]

49. Dunn AJ, Wang J, Ando T. Effects of cytokines on cerebral neurotransmission. Comparison with the effects of stress. Adv Exp Med Biol. 1999; 461:117-27. [PubMed: 10442171]

50. Hayley S, Merali Z, Anisman H. Stress and cytokine-elicited neuroendocrine and neurotransmitter sensitization: implications for depressive illness. Stress. 2003; 6(1):19-32. [PubMed: 12637204]

51. Yirmiya R, Goshen I. Immune modulation of learning, memory, neural plasticity and neurogenesis. Brain Behav Immun. 2011; 25(2):181-213. [PubMed: 20970492]

52. Baune B, Camara M-L, Eyre H, et al. Tumour necrosis factor - alpha mediated mechanisms of cognitive dysfunction. Translational Neuroscience. 2012; 3(3):263-277.

53. Stellwagen D, Malenka RC. Synaptic scaling mediated by glial TNF-alpha. Nature. 2006; 440(7087):1054-9. [PubMed: 16547515]

54. Warner-Schmidt JL, Vanover KE, Chen EY, et al. Antidepressant effects of selective serotonin reuptake inhibitors (SSRIs) are attenuated by antiinflammatory drugs in mice and humans. Proc Natl Acad Sci U S A. 2011; 108(22):9262-7. [PubMed: 21518864]

55. Dantzer R, O'Connor JC, Freund GG, et al. From inflammation to sickness and depression: when the immune system subjugates the brain. Nat Rev Neurosci. 2008; 9(1):46-56. [PubMed: 18073775]

56. O'Connor JC, Lawson MA, Andre C, et al. Lipopolysaccharide-induced depressive-like behavior is mediated by indoleamine 2,3-dioxygenase activation in mice. Mol Psychiatry. 2008

57. O'Connor JC, Lawson MA, Andre C, et al. Induction of IDO by bacille Calmette-Guerin is responsible for development of murine depressive-like behavior. J Immunol. 2009; 182(5):320212. [PubMed: 19234218]

58. Bonaccorso S, Marino V, Puzella A, et al. Increased depressive ratings in patients with hepatitis C receiving interferon-alpha-based immunotherapy are related to interferon-alpha-induced changes in the serotonergic system. J Clin Psychopharmacol. 2002; 22(1):86-90. [PubMed: 11799348]

59. Capuron L, Neurauter G, Musselman DL, et al. Interferon-alpha-induced changes in tryptophan metabolism relationship to depression and paroxetine treatment. Biol Psychiatry. 2003; 54(9):90614. [PubMed: 14573318]

60. Haroon E, Raison CL, Miller AH. Psychoneuroimmunology meets neuropsychopharmacology: translational implications of the impact of inflammation on behavior. Neuropsychopharmacology. 2012; 37(1):137-62. [PubMed: 21918508]

61. Capuron L, Schroecksnadel S, Feart C, et al. Chronic low-grade inflammation in elderly persons is associated with altered tryptophan and tyrosine metabolism: role in neuropsychiatric symptoms. Biol Psychiatry. 2011; 70(2):175-82. [PubMed: 21277567]

62. Neurauter G, Schrocksnadel K, Scholl-Burgi S, et al. Chronic immune stimulation correlates with reduced phenylalanine turnover. Curr Drug Metab. 2008; 9(7):622-7. [PubMed: 18781914]

63. Neurauter G, Grahmann AV, Klieber M, et al. Serum phenylalanine concentrations in patients with ovarian carcinoma correlate with concentrations of immune activation markers and of isoprostane-8. Cancer Lett. 2008; 272(1):141-7. [PubMed: 18701209]

64. Felger JC, Li L, Marvar PJ, et al. Tyrosine metabolism during interferon-alpha administration: Association with fatigue and CSF dopamine concentrations. Brain Behav Immun. 2012

65. Cunnington C, Channon KM. Tetrahydrobiopterin: pleiotropic roles in cardiovascular pathophysiology. Heart. 2010; 96(23):1872-7. [PubMed: 20837663] 
66. Kitagami T, Yamada K, Miura H, et al. Mechanism of systemically injected interferon-alpha impeding monoamine biosynthesis in rats: role of nitric oxide as a signal crossing the blood-brain barrier. Brain Res. 2003; 978(1-2):104-14. [PubMed: 12834904]

67. Zhu CB, Blakely RD, Hewlett WA. The proinflammatory cytokines interleukin-1beta and tumor necrosis factor-alpha activate serotonin transporters. Neuropsychopharmacology. 2006; 31(10): 2121-31. [PubMed: 16452991]

68. Zhu CB, Carneiro AM, Dostmann WR, et al. p38 MAPK activation elevates serotonin transport activity via a trafficking-independent, protein phosphatase $2 \mathrm{~A}$-dependent process. J Biol Chem. 2005; 280(16):15649-58. [PubMed: 15728187]

69. Zhu CB, Lindler KM, Owens AW, et al. Interleukin-1 receptor activation by systemic lipopolysaccharide induces behavioral despair linked to MAPK regulation of CNS serotonin transporters. Neuropsychopharmacology. 2010; 35(13):2510-20. [PubMed: 20827273]

70. Sanchez MM, Alagbe O, Felger JC, et al. Activated p38 MAPK is associated with decreased CSF 5-HIAA and increased maternal rejection during infancy in rhesus monkeys. Mol Psychiatry. 2007; 12(10):895-7. [PubMed: 17895923]

71. Moron JA, Zakharova I, Ferrer JV, et al. Mitogen-activated protein kinase regulates dopamine transporter surface expression and dopamine transport capacity. J Neurosci. 2003; 23(24):8480-8. [PubMed: 13679416]

72. Capuron L, Pagnoni G, Drake DF, et al. Dopaminergic mechanisms of reduced Basal Ganglia responses to hedonic reward during interferon alfa administration. Arch Gen Psychiatry. 2012; 69(10):1044-53. [PubMed: 23026954]

73. Wu HQ, Rassoulpour A, Schwarcz R. Kynurenic acid leads, dopamine follows: a new case of volume transmission in the brain? J Neural Transm. 2007; 114(1):33-41. [PubMed: 16932989]

74. Albuquerque EX, Schwarcz R. Kynurenic acid as an Antagonist of alpha7 Nicotinic Acetylcholine Receptors in the Brain: Facts and Challenges. Biochem Pharmacol. 2012

75. Ida T, Hara M, Nakamura Y, et al. Cytokine-induced enhancement of calcium-dependent glutamate release from astrocytes mediated by nitric oxide. Neurosci Lett. 2008; 432(3):232-6. [PubMed: 18255223]

76. Matute C, Domercq M, Sanchez-Gomez MV. Glutamate-mediated glial injury: mechanisms and clinical importance. Glia. 2006; 53(2):212-24. [PubMed: 16206168]

77. Hardingham GE, Fukunaga Y, Bading H. Extrasynaptic NMDARs oppose synaptic NMDARs by triggering CREB shut-off and cell death pathways. Nat Neurosci. 2002; 5(5):405-14. [PubMed: 11953750]

78. Lee M, Schwab C, McGeer PL. Astrocytes are GABAergic cells that modulate microglial activity. Glia. 2011; 59(1):152-65. [PubMed: 21046567]

79. Bhat R, Axtell R, Mitra A, et al. Inhibitory role for GABA in autoimmune inflammation. Proc Natl Acad Sci U S A. 2010; 107(6):2580-5. [PubMed: 20133656]

80. Rossi S, Studer V, Motta C, et al. Inflammation inhibits GABA transmission in multiple sclerosis. Mult Scler. 2012; 18(11):1633-5. [PubMed: 22419673]

81. Li Y, Liu L, Kang J, et al. Neuronal-glial interactions mediated by interleukin-1 enhance neuronal acetylcholinesterase activity and mRNA expression. J Neurosci. 2000; 20(1):149-55. [PubMed: 10627591]

82. Rada P, Mark GP, Vitek MP, et al. Interleukin-1 beta decreases acetylcholine measured by microdialysis in the hippocampus of freely moving rats. Brain Res. 1991; 550(2):287-90. [PubMed: 1884236]

83. Pavlov VA, Parrish WR, Rosas-Ballina M, et al. Brain acetylcholinesterase activity controls systemic cytokine levels through the cholinergic anti-inflammatory pathway. Brain Behav Immun. 2009; 23(1):41-5. [PubMed: 18639629]

84. O'Connor MF, Irwin MR, Wellisch DK. When grief heats up: Pro-inflammatory cytokines predict regional brain activation. Neuroimage. 2009; 47(3):891-896. [PubMed: 19481155]

85. Juengling FD, Ebert D, Gut O, et al. Prefrontal cortical hypometabolism during low-dose interferon alpha treatment. Psychopharmacology (Berl). 2000; 152(4):383-9. [PubMed: 11140330] 
86. Satizabal CL, Zhu YC, Mazoyer B, et al. Circulating IL-6 and CRP are associated with MRI findings in the elderly: the 3C-Dijon Study. Neurology. 2012; 78(10):720-7. [PubMed: 22357713]

87. Capuron L, Pagnoni G, Demetrashvili MF, et al. Basal ganglia hypermetabolism and symptoms of fatigue during interferon-alpha therapy. Neuropsychopharmacology. 2007; 32(11):2384-92. [PubMed: 17327884]

88. Eidelberg D, Moeller JR, Dhawan V, et al. The metabolic topography of parkinsonism. J Cereb Blood Flow Metab. 1994; 14(5):783-801. [PubMed: 8063874]

89. Wichmann T, DeLong MR. Functional neuroanatomy of the basal ganglia in Parkinson's disease. Adv Neurol. 2003; 91:9-18. [PubMed: 12442660]

90. Wichmann T, DeLong MR. Oscillations in the basal ganglia. Nature. 1999; 400(6745):621-2. [PubMed: 10458157]

91. Bersano A, Aghemo A, Rumi MG, et al. Recovery after L-DOPA treatment in peginterferon and ribavirin induced parkinsonism. Eur J Intern Med. 2008; 19(5):370-1. [PubMed: 18549943]

92. Majer M, Welberg LA, Capuron L, et al. IFN-alpha-induced motor slowing is associated with increased depression and fatigue in patients with chronic hepatitis C. Brain Behav Immun. 2008; 22(6):870-80. [PubMed: 18258414]

93. Hadjiconstantinou M, Wemlinger TA, Sylvia CP, et al. Aromatic L-amino acid decarboxylase activity of mouse striatum is modulated via dopamine receptors. J Neurochem. 1993; 60(6):217580. [PubMed: 8492125]

94. Carter CS, Braver TS, Barch DM, et al. Anterior cingulate cortex, error detection, and the online monitoring of performance. Science. 1998; 280(5364):747-9. [PubMed: 9563953]

95. Eisenberger NI, Lieberman MD. Why rejection hurts: a common neural alarm system for physical and social pain. Trends Cogn Sci. 2004; 8(7):294-300. [PubMed: 15242688]

96. Critchley HD, Tang J, Glaser D, et al. Anterior cingulate activity during error and autonomic response. Neuroimage. 2005; 27(4):885-95. [PubMed: 15996878]

97. Capuron L, Pagnoni G, Demetrashvili M, et al. Anterior cingulate activation and error processing during interferon-alpha treatment. Biol Psychiatry. 2005; 58(3):190-6. [PubMed: 16084839]

98. Paulus MP, Feinstein JS, Simmons A, Stein MB. Anterior cingulate activation in high trait anxious subjects is related to altered error processing during decision making. Biol Psychiatry. 2004; 55(12):1179-87. [PubMed: 15184037]

99. Eisenberger NI, Lieberman MD, Satpute AB. Personality from a controlled processing perspective: an fMRI study of neuroticism, extraversion, and self-consciousness. Cogn Affect Behav Neurosci. 2005; 5(2):169-81. [PubMed: 16180623]

100. Ursu S, Stenger VA, Shear MK, et al. Overactive action monitoring in obsessive-compulsive disorder: evidence from functional magnetic resonance imaging. Psychol Sci. 2003; 14(4):34753. [PubMed: 12807408]

101. Slavich GM, Way BM, Eisenberger NI, Taylor SE. Neural sensitivity to social rejection is associated with inflammatory responses to social stress. Proc Natl Acad Sci U S A. 2010; 107(33):14817-22. [PubMed: 20679216]

102. Raison CL, Miller AH. The evolutionary significance of depression in Pathogen Host Defense (PATHOS-D). Mol Psychiatry. 2013; 18(1):15-37. [PubMed: 22290120]

103. Miller AH. Norman Cousins Lecture. Mechanisms of cytokine-induced behavioral changes: psychoneuroimmunology at the translational interface. Brain Behav Immun. 2009; 23(2):149-58. [PubMed: 18793712] 


\section{Hypervigilance (protection from attack)}

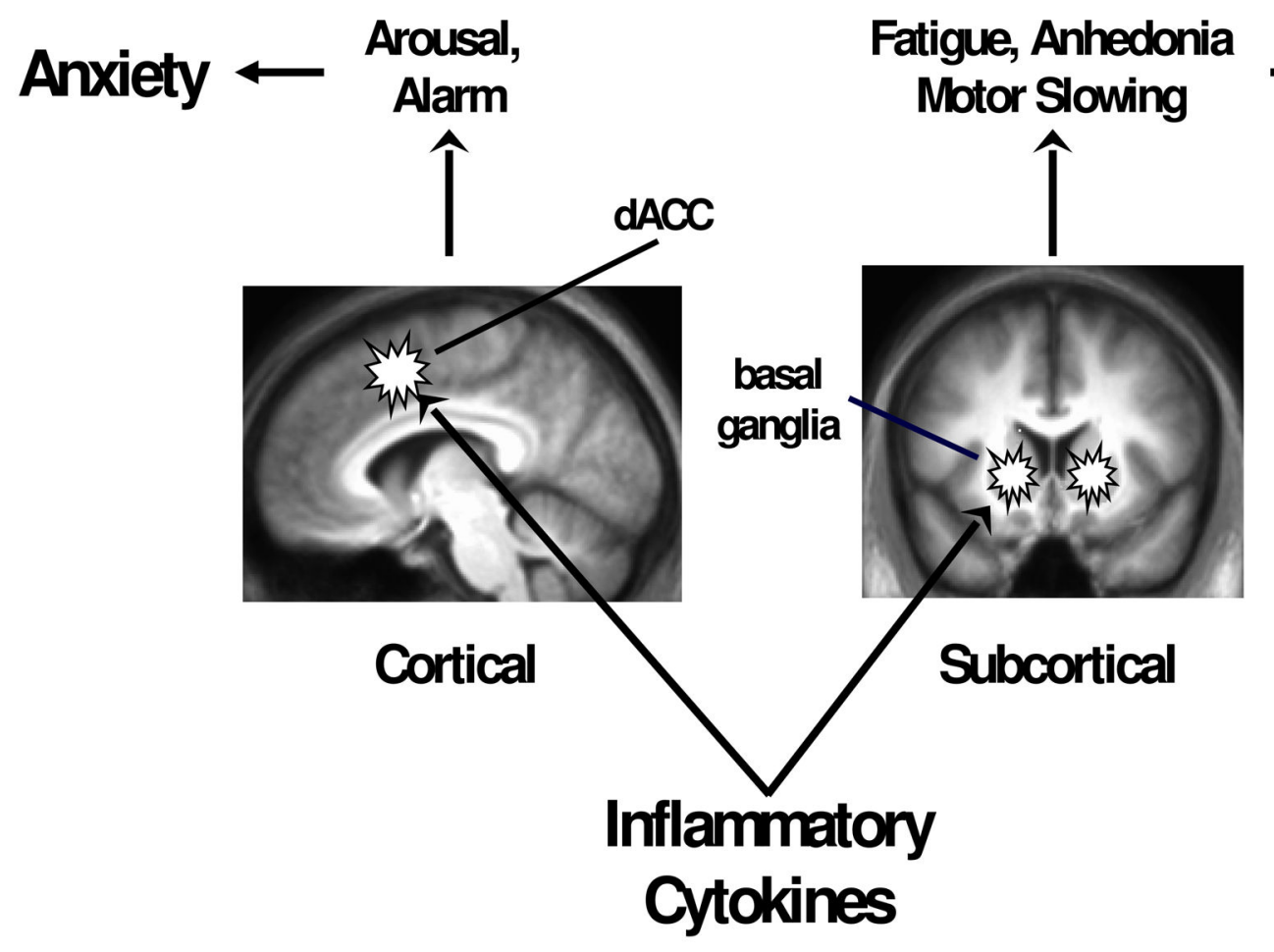

Withdrawal

(wound healing, infection fighting)

Figure 1. Effects of Inflammatory Cytokines on the Brain: Evolutionary Advantages and Psychiatric Cbrosts

Findings from neuroimaging studies in humans indicate that inflammatory cytokines can alter the function of key subcortical and cortical circuits that lead to conservation/ withdrawal (basal ganglia) and hypervigilence (dorsal anterior cingulate cortex - dACC). These behavioral responses have evolved to play an essential role in the highly integrated behavioral and immune response to infectious challenge and/or physical trauma. However, in the modern world, chronic activation of these responses can contribute to the development of disorders of depression and anxiety. 